\title{
An investigation on supercapacitors applications with module designing and testing
}

\author{
Mustafa Ergin Şahin \\ Department of Electrical and Electronics Engineering, Recep Tayyip Erdoğan University, Rize, Turkey \\ Corresponding Author: mustafaerginsahin@yahoo.com
}

Submitted : 27/08/2020

Revised : 30/04/2021

Accepted :23/05/2021

\begin{abstract}
Supercapacitors have high power density and some advantages than other storage devices. Therefore, the applications of supercapacitors and investigations to develop their materials and chemistry are increasing every day. Also, the engineering and energy storage applications of supercapacitors are being continuously researched. The structural properties of supercapacitors and their technical applications based on an extensive literature review are given in this paper firstly. Then, requirements for module design for supercapacitors are revealed, and module design is carried out and set up. The supercapacitor module design is performed in MATLAB/Simulink software, and the simulation results are obtained for the charge and discharge conditions. Measurements are performed at various load conditions, and results are compared with simulation results and rated with supercapacitor manufacturers' datasheets. The power storage capacity of supercapacitor modules and discharging as a function of time is obtained experimentally. These results give us information about the power density of supercapacitors for different loads, and how long and how much the current can be given. This study can be considered as a preliminary study on supercapacitors to be used in power electronics, renewable energy, and electric vehicle applications, instead of conventional energy storage techniques. The detailed review of the literature and the obtained data in the present paper shed light on further studies to be performed in the field.
\end{abstract}

Keywords: Current storage technologies; Supercapacitors applications; Supercapacitor module design; Modelling of supercapacitor; Charge and discharge tests of supercapacitors.

\section{INTRODUCTION}

Supercapacitors (SCs) were used for many years in wind turbines, mobile base stations, electronic devices, and different industrial practices (Libich et al., 2018, Kuperman et al., 2012, Bottu et al., 2012). On the other hand, they have started to be used in uninterruptible power supplies, electric vehicles, and various power electronics applications thanks to their superiority over the lead-acid batteries recently (Eroğlu, 2010, Schneuwly, 2015, Lee, 2015). In recent years, the SCs are used as energy storage devices for voltage stability in renewable and hybrid energy storage systems to regulate the source and grid side (Rawat et al., 2019, Shuai et al., 2020, Şahin et al., 2020).

When the superiorities of supercapacitors are observed firstly, it can be realized that they can store the same amount of power in a smaller volume compared to a battery (Eroğlu, 2010, Ortúzar, 2005). Supercapacitors get less affected by impulse currents, and they can decrease these impulse currents. The most important reason for that is 
their ability to make a fast charge and discharge. Batteries get worn out in these processes. Whereas SCs can be charged/discharged for hundreds of thousands of times, batteries can be charged/discharged for a thousand times at the most, and they lose their properties with time (Zhang et al., 2018). Another specification of SCs is that they have very low internal resistance and much higher volume (Sahin et al., 2020). While SCs can be charged/discharged within a range from zero volting up to the allowed value, it is difficult to do the same with the batteries. Batteries get damaged if they are overcharged or overdischarged (Sahin et al., 2021). Therefore, a wide range of bus voltage can be selected. The charge level of SCs is directly related to the capacitor and voltage value, and it can easily be detected, but it is difficult to detect the level of charge in batteries. Again, the operation temperature range of supercapacitors is quite wide (Kreczanik et al., 2013, Headquarter, 2013). This level can decrease to $-10{ }^{\circ} \mathrm{C}-40{ }^{\circ} \mathrm{C}$ range in supercapacitors (URL 1, 2020, URL 2, 2020, Prummer et al., 2015). Also, temperature, voltage, and currents are the main parameters that accelerate the aging of SC (Kreczanik et al., 2013).

When the literature on SCs is considered, it can be seen that these studies can be divided into three groups, and it would be more appropriate to deal with them in groups. The first group of studies mainly describes the characteristics of SCs and testing of these characteristics. The second group of studies is based on the applications of supercapacitors in automotive, hybrid vehicles, and the transportation industries. The third group is those who are dedicated to renewable power sources and the network-related systems and their power electronics applications.

\section{A. Basics and Characteristic Properties of Super Capacitors}

The studies conducted on the basics and characteristic properties of supercapacitors were considered here. In one of these studies, temperature and dynamic programs of supercapacitors were investigated, and their efficiency changes were analyzed (Hartmut, 2006). It was emphasized that a cooler unit was necessary for module designs. In another study conducted on the characteristics and modelling of supercapacitors, this method was analyzed for utilization of sudden power need, and impulse, frequency, and voltage rates were determined in the first place for the hybrid electric vehicles (Lajnef et al., 2007). The dynamic behavior of supercapacitors was the focus of interest initially. Then, a dynamic model was created for supercapacitors, and the results obtained were compared for different parameters. A study conducted on capacity and leakage current balancing for supercapacitors focused on the voltage imbalance observed in supercapacitor modules for different capacity values and different leakage resistance (Latkovskis et al., 2012). The study offered a solution that decreases the imbalance of cell voltages and increases the storing efficiency of supercapacitor modules utilizing capacitor balance and passive resistance voltage balance. The efficiency of the method was theoretically proven and tested on eight capacitor modules. The theoretical and experimental results obtained show that the capacitance balancing in parallel/series SC connection significantly improves the effective energy capacity of the SC bank (Latkovskis et al., 2012). In another study that was conducted to test the lifetimes of supercapacitors when used for long periods, a MATLAB/Simulink software installed computer-controlled testing apparatus was designed to check whether the lifetimes specified by the manufacturers were true or not (Murray et al., 2015). This study also defined the temperature changes of supercapacitors and their impact on their lifetime. Supercapacitors are tested in normal operating conditions for two years and up to ten million cycles. It was observed that supercapacitors operated within the specified tolerance range without any trouble. These results confirmed the manufacturer's catalogs and showed that supercapacitors could be used in applications that require long lifetimes. A virtual laboratory is performed to test the characteristics of supercapacitors and batteries, applications of supercapacitors, and battery energy storage components (Freeman et al., 2013). The setup allowed the users to reveal the charging/discharging capacities of different types of batteries and supercapacitors. The study brought new ideas and enabled observation of the number of energy stores. Some other studies about the characteristics of supercapacitors will be mentioned in the modelling section. 


\section{B. The Electrical Vehicle Applications of Supercapacitors}

The studies conducted on the electrical vehicle applications of supercapacitors were also reviewed. In a study conducted by Cyrus et al. on electrical vehicle applications, the automotive applications of supercapacitors were reviewed, and the supercapacitor module was projected to be connected in parallel with the output load (Cyrus et al., 2006). Characteristics of different supercapacitors were studied and compared, their charging/discharging test graphics were drawn, and several comparisons were made. Subsequently, potential applications in the automotive industry were identified, and a consensus requirement specification was drawn as a development guide for the industry (Cyrus et al., 2006). In another study conducted by Steiner et al., supercapacitor supported energy storing systems for tramway vehicles were addressed (Steiner et al., 2007). This system, which had been in use since 2003, was observed to provide around 30\% energy saving. It also had other benefits including decreasing the peak flow need, enabling the trains to go hundreds of meters without the need for energy, and enabling cost-free charging stations at stops. With the help of the latest technologies, researchers of today are trying to develop systems that can store $600 \mathrm{~kW}$ energy in 16 seconds at every stop (Matthias et al. 2015). Some other studies conducted by Paseran et al. (2005), Anstrom et al. (2005), and Farzad et al. (2011) dealt with the systems where batteries and supercapacitors were connected in parallel for the charging systems of the electrical vehicles. In the first study, battery and supercapacitor properties needed for the electrical vehicles were determined, and the potential results of their coutilization were revealed out. The results were tested with an eight-cell supercapacitor module (Paseran et al., 2005). In the other study, simulation studies and field tests were conducted for supercapacitor and battery charge systems of hybrid and electric vehicles. It was observed at the end of several tests that supercapacitors enabled significant improvements in peak flow as a spare source for batteries (Anstrom et al., 2005). The third study dealt with the modelling of a charge station for dual direction DC/DC converter and hybrid electric vehicles and determination of its benefits. That study aimed to lower the costs of the electric vehicle charge stations and to show the increase in high energy density and efficiency of the hybrid system by making use of Li-ion battery supercapacitor and two DC/DC converters. The result revealed that the hybrid energy storing system performed better than batteries and supercapacitors in the procurement of high energy and energy density (Farzad et al., 2011). Various energy storage systems (ESS) specifications meeting in the electric vehicles 42V Start-Stop minimum requirements are shown in Table 1.

Tablo 1. Various ESS specifications meeting the 42V start-stop (Paseran et al., 2005).

\begin{tabular}{|c|c|c|c|c|c|c|c|c|c|}
\hline 竞 & 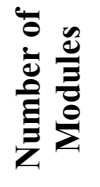 & 导 & 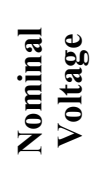 & $\stackrel{0}{0}$ & $\begin{array}{l}\bar{D} \\
\vdots \\
0 \\
0 \\
0 \\
0\end{array}$ & 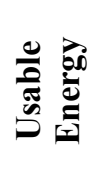 & $\sum^{\infty}$ & $\dot{\tilde{y}}$ & $\frac{\mathscr{\Xi}}{\bar{\Xi}}$ \\
\hline Units & - & - & V & $\mathrm{kW}$ & $\mathrm{kW}$ & Wh & $\mathrm{kg}$ & $\$$ & $\mathrm{~L}$ \\
\hline PbA only & 3 & 1 & 37.89 & 7.8 & 7.85 & 256.7 & 33.0 & 330 & 11.6 \\
\hline UC only (2600 F) & 20 & 1 & 39.5 & 14 & 54 & 35.0 & 14.2 & 600 & 21.7 \\
\hline Li-ion (6Ah) & 22 & 2 & 40.93 & 12.1 & 12.1 & 156.7 & 8.3 & 440 & 6.6 \\
\hline NiMH (6.5 Ah) & 10 & 2 & 39.78 & 7 & 7.8 & 125.0 & 10.0 & 400 & 8.8 \\
\hline $\begin{array}{c}3 \mathrm{PbA}+7 \mathrm{UC} \\
(\mathrm{PbA} @ \mathbf{H V})\end{array}$ & $(3+7)$ & $\mathrm{n} / \mathrm{a}$ & 37.89 & 12.5 & 27 & 271.7 & 46.4 & 847 & 22.0 \\
\hline
\end{tabular}


The objective of another Ph.D. thesis research is to develop suitable models to simulate and analyze Electrical Vehicle (EV) power-trains to identify and improve some of the deficiencies of EVs and investigate new system architectures. Multiple energy source systems are modelled and studied in the form of an energy-dense ZEBRA battery technology connected in parallel with a power-dense supercapacitor system. This study offers a suitable model for different energy sources and then optimizes the vehicle energy storage combination to realize its full potential (Jarushi, 2010). A book study about environmental impact and history of a modern vehicle with fundamentals is given first. HEVs and their energy storage system with supercapacitors are given in this book. The future of supercapacitors, basic principles, performance, and supercapacitor technologies are investigated in more detail in the chapters of this book (Ehsani et al., 2018).

\section{Other Utilization Areas of Supercapacitors}

Other utilization areas of supercapacitors such as smart networks, renewable energy, and power electronics were also reviewed in this chapter. Firstly, the energy sources modelling of hybrid electrical vehicles given in the study conducted by Van Mierlo et al. (2004) dealt with the fuel cells, battery, supercapacitor, and flywheel motor described. The advantages and properties and the equivalent model of the supercapacitor component were presented. Nevertheless, this study was not comprehensive, and it did not sufficiently investigate the supercapacitor components. The study conducted by Miller et al. (2010) focused on supercapacitor and battery as a hybrid energy-storing model. The type of power electronics converter setup needed for the provision of such a hybrid system, and the necessary properties were dealt with. Simulations were made for utilization in different converter structures and electric vehicles, and the results were compared. In another study, the maximum charge condition of the supercapacitor of the switched rectifier for one circuit was studied (Kleas, 2005). An algorithm that regulated the duty cycle of the DC/DC Buck-Boost Converter was designed to enable the synchronous generator to work at the maximum power point when being charged with supercapacitor, and simulations were made. In another study conducted by Daboussi et al. (2007), a Lithium-ion-Supercapacitor hybrid energy module that included some simulations and experimental results was presented. An optimized Li-ion/ultra-capacitor Hybrid Energy Module (HEM) is presented in this paper to determine the optimum utilization of ultra-capacitors in hybrid vehicle and space applications where high power density and high energy density are required. In another study conducted by Wei et al. (2011), DC micro-networks were emphasized as a candidate that would fulfill the needs of the smart networks of the future, and it was stated that the most significant issue here was to go beyond the ordinary production and to work with maximum efficiency by making using of renewable energy and storing and by minimizing the cost. The two load sharing methods as the subsequent and parallel are presented in DC/DC converters for multisource input in this article. Experimental and simulation studies that showed the impact of this new method are given (Wei et al., 2011). Finally, this study presents the reduction in battery stresses by using SCs in a $500 \mathrm{kVA}$ rated UPS. The authors investigate the optimal supercapacitors, battery combination versus the SCs cost. The SCs and battery models developed using MATLAB/Simulink are presented and validated. The architecture and simulation of the designed system that combines the SCs and battery were shown. The supercapacitors were used as high power storage devices to smooth the peak power applied to the battery (Lahyani et al., 2012; Sahin et al., 2021).

In the conclusion of this chapter, the utilization of supercapacitors seems quite useful considering the superiorities of supercapacitors. On the other hand, there are also some disadvantages. First of all, the SCs cost too much; however, new technologies are being researched to decrease the prices of these products by the manufacturers and scientists. But this can be compensated by its long-term charging/discharging property. Another disadvantage is that supercapacitors have a higher power density than batteries, yet a lower energy density (Headquarter, 2013). The performance analyses of lead-acid, lithium-ion batteries, and supercapacitors are compared in Table 2 (Jing et al., 2016; URL 3, 2020, Glavin et al., 2008; Manandhar et al., 2017). 
Table 2. Performance analyses of lead-acid, lithium-ion batteries, and supercapacitors.

\begin{tabular}{|c|c|c|c|}
\hline Parameters & Lead-acid Battery & Lithium-ion Battery & Supercapacitor \\
\hline The specific energy density (Wh/kg) & $10-100$ & $150-200$ & $1-10$ \\
\hline Specific power density (W/kg) & $<1000$ & $<2000$ & $<10000$ \\
\hline Cycle life (cycles) & 1000 & 5000 & $>500000$ \\
\hline Charge discharge efficiency & $70-85 \%$ & $99 \%$ & $85-98 \%$ \\
\hline Fast charge time & $1-5$ hours & $0.5-3$ hours & $0.3-30 \mathrm{sec}$ \\
\hline Discharge time & $0.3-3$ hours & $0.3-3$ hours & $0.3-30 \mathrm{sec}$ \\
\hline Calendar life (year) & $5-15$ & $10-20$ & 20 \\
\hline Cost & Low & High & Medium \\
\hline
\end{tabular}

Considering the advantages and disadvantages of SC, it seems the most rational thing to install a system in an appropriate voltage and power value where the two systems are used together (Libich et al., 2018, Kuperman et al., 2012, Schneuwly, 2015, Lahyani et al., 2012).

In this papar, firstly, a detailed literature review is made about SC and their applications. Within this framework, supercapacitor values suitable for the established system power that would ensure the necessary bus voltage were selected, and these capacities were used to design a supercapacitor module that would meet the need in different voltages $(12 \mathrm{~V}, 24 \mathrm{~V}, 48 \mathrm{~V})$. Different load conditions of supercapacitors were considered for these operating conditions, and the charging-discharging tests were conducted. The supercapacitor modules were tested, compared, and rated with the alone supercapacitors and MATLAB/Simulink simulation results.

\section{METHODS AND MATERIAL}

\subsection{The Structure and Properties of Supercapacitors}

Today, supercapacitors are produced in different properties by several manufacturers (URL 1, 2020, URL 2, 2020). They are produced by different voltage and capacity ranges for different applications. Also, they include coin type, winding type, combined type, module, high-temperature SC, and hybrid capacitor (URL 5, 2020, URL 6, 2020). Market research was made, and Maxwell brand BCAP0310 model $310 \mathrm{~F}$ and $2.7 \mathrm{~V}$ charging voltage supercapacitors that could be mounted on the printed circuit were selected for the design. Looking at the catalog data, it is observed that these capacities have $2.2 \mathrm{~m} \Omega$ ESRDC resistance, and they can be supplied by $2.85 \mathrm{~V}$ voltage, and the continuous current is $25 \mathrm{~A}$ for $15^{\circ} \mathrm{C}$. The peak current of this SCs for one second is $250 \mathrm{~A}$, the maximum leakage current is 0.45 $\mathrm{mA}$, and it can preserve its voltage for 72 hours in normal conditions. Furthermore, it is observed to be able to work from -40 to $+70{ }^{\circ} \mathrm{C}$. Each of them has $61.5 \mathrm{~mm}$ in height and $3.3 \mathrm{~cm}$ in diameter (URL 1, 2020).

The image of the SCs used for module design and the electrical equivalent circuit model are given in Figure 1. The series resistance $\left(R_{s}\right)$ here represents the equivalent series resistance (ESR), whereas the parallel resistance $\left(R_{p}\right)$ 
represents the resistance estimated according to the leakage currents, and the capacitance $\left(C_{\mathrm{UC}}\right)$ represents the total capacitance of SCs.

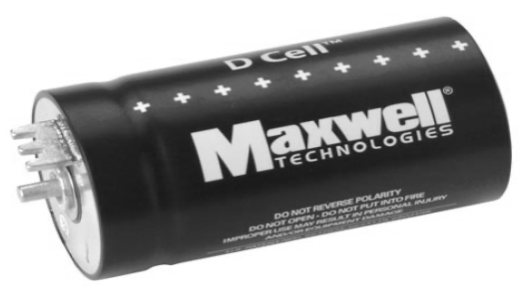

(a)

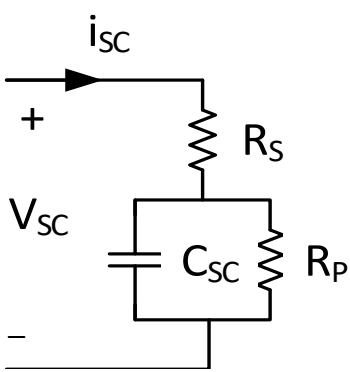

(b)

Figure 1. The image of used supercapacitor (a), equivalent circuit model (b) (URL 1, 2020).

The above parameters mentioned in the catalog data can be used to calculate the values in the following equations (URL 1, 2013). The maximum instant current in a second and the other necessary values can be calculated by making use of the Equations 1 to 4 .

Maximum Peak Current $(1 \mathrm{sec})=\frac{1 /{ }_{2} \cdot \mathrm{C} \cdot \mathrm{V}}{\mathrm{C} . E S R_{\mathrm{DC}}+1}$

$\mathrm{P}_{\max }($ Specific Power $)=\frac{\mathrm{V}^{2}}{4 \cdot \mathrm{ESR}_{\mathrm{DC}} \cdot \mathrm{mass}}$

$\mathrm{E}_{\max }\left(\right.$ Specific Energy) $=\frac{1 /{ }_{2} \cdot \mathrm{C} \cdot \mathrm{V}^{2}}{3,600 \cdot \operatorname{mass}}$

$\mathrm{E}_{\mathrm{S}}($ Storable Energy $)=\frac{1 / 2 \cdot \mathrm{C} \cdot \mathrm{V}^{2}}{3,600}$

\subsection{Modelling and Simulation of the Supercapacitor Module}

There are several studies in the literature where chemical, mathematical, and electrical stimulation of supercapacitors were investigated (Johansson et al. 2008, Michalczuk et al., 2015, $\quad$ Faranda et al., 2007, Shah et al., 2012, Buller et al., 2002, Cheng et al., 2010, Islam et al., 2010, Zubieta et al., 2000). The module simulation was based on the most comprehensive of these studies, which also included the module structure and its mathematical equation simulation (Seim, 2011, Oldham, 2008, Riley, 2011, Monzer et al., 2010). The chemical structure of SC modules and the chemical and electrical reactions during charging are illustrated in Figure 2. As being different from other condensers, the separators were utilized, and a structurally different dual-layer capacitor is seen (Seim, 2011). Nanomaterials are started to be used in SC design today, and the preparation of nanoporous iron oxide/carbon composites provides a highly accessible path for the diffusion of electrolyte ions (Azhar et al., 2019). 

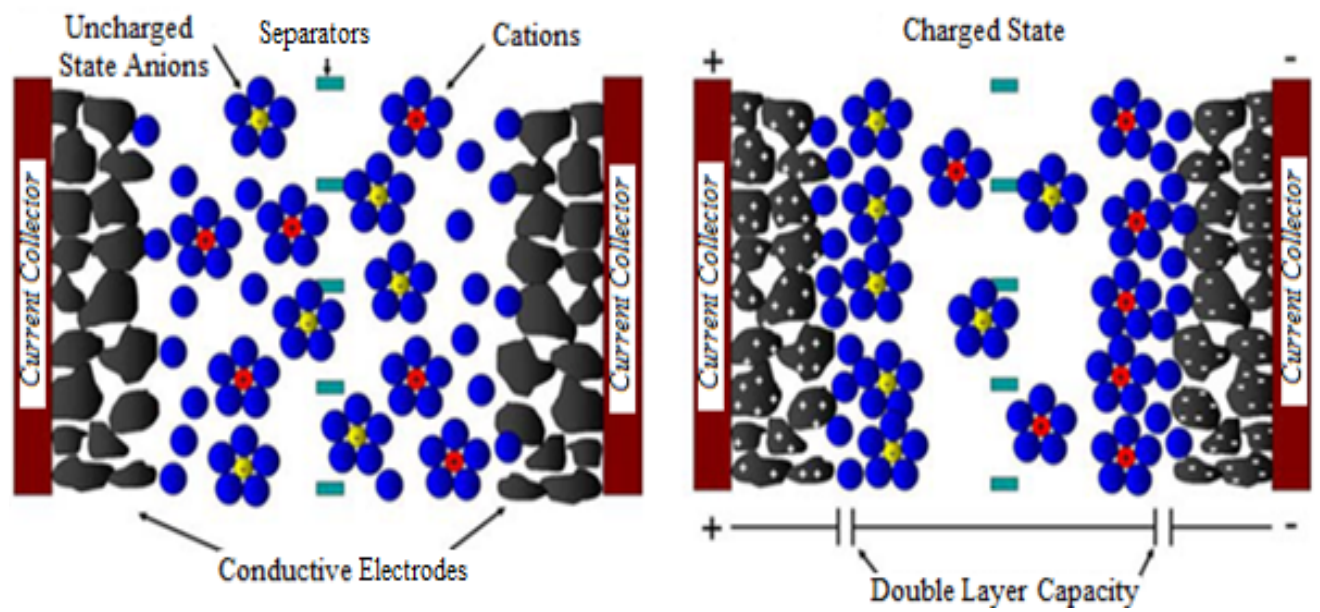

Figure 2. Chemical structure of supercapacitor for the uncharged and charged states (Azhar et al., 2019).

In a study, the dual-layer capacitor model was developed for two different structures (Oldham, 2008). According to this model, the potential difference between the metal-electrolyte solutions for electrolyte solution structure can be written as in Equation 5. Descriptions regarding the variables valid for Equations 5 to 9 are given in Table 3.

$$
V=\frac{q \cdot d}{\varepsilon}+\frac{2 R T}{F} \operatorname{arsinh}\left\{\frac{q}{\sqrt{8 R T \varepsilon C}}\right\}
$$

Based on this mathematical model, the total potential difference belonging to the block structure obtained through a serial and parallel connection of supercapacitors can be written as in Equation 6.

$V_{T}=\frac{N_{S} Q_{T} d}{N_{p} N_{e} \varepsilon \varepsilon_{0} A_{i}}+\frac{2 N_{e} N_{S} R T}{F} \operatorname{arsinh}\left\{\frac{Q_{T}}{\sqrt{8 R T \varepsilon \varepsilon_{0} c}}\right\}$

The current of a supercapacitor is can be written as in Equation 7.

$i=i_{\mathrm{sc}} \cdot(1-u(t))+i_{\text {self_dis }} \cdot u(t)$

Based on these equations, the equivalent circuit model belonging to the most commonly used supercapacitor block is given in Figure 3 (a) (Riley, 2011, URL 3, 2020).

Equation 8 is observed between the super capacitor's total load and current for $i_{s c}=0$. The $I_{\text {self dis }}$ current is given as in Equation 9. The $\alpha$ value in this equation is a fixed value, and it is related to the change observed in the voltage rate of supercapacitor in time.

$$
\begin{aligned}
& Q_{T}=\int \dot{\mathrm{I}}_{\mathrm{SC}} d t \text { and } Q_{T}=\int \mathrm{i}_{\text {self_dis }} d t\left(\text { for } i_{\mathrm{sc}}=0\right) \\
& i_{\text {self_dis }}=\frac{C_{T} \alpha}{1+s R_{S C} C_{T}}
\end{aligned}
$$


Table 3. Descriptions for the variables used in the supercapacitor model.

\begin{tabular}{|c|c|c|c|}
\hline Variable & Description & Variable & Description \\
\hline$A_{\mathrm{I}}$ & $\begin{array}{c}\text { Surface area between the electrode } \\
\text { and electrolyte }\left(\mathrm{m}^{2}\right)\end{array}$ & $R_{\mathrm{sc}}$ & Total resistance \\
\hline$c$ & Molar condensation & $N e$ & Electrode plates number \\
\hline$F$ & Faraday constant & $N A$ & Avogadro number constant \\
\hline$i_{\mathrm{sc}}$ & Supercapacitor current (A) & $N p$ & Parallel supercapacitors numbers \\
\hline$V_{\mathrm{SC}}$ & Supercapacitor potential (V) & $N S$ & Series supercapacitor numbers \\
\hline$C_{T}$ & Total capacity & $Q T$ & Electrical Capacity (C) \\
\hline$R$ & Ideal gas constant & $d$ & Molecular permeability \\
\hline$T$ & Study temperature (K) & $\varepsilon, \varepsilon_{o}$ & Material's and air permeability \\
\hline
\end{tabular}

The supercapacitor MATLAB/Simulink functional model with the charge and discharge setup is given in Figure 3 (b). The simulation setup is designed with a similar experimental setup to be compared to the simulation and experimental results. The simulation results for a single capacitor charge/discharge conditions current, voltage, and power curves for different load and ESR conditions $(0$ to $1 \Omega$ ) are given in Figure 4 (a-d). The simulation results for five series-connected capacitor single module charge-discharge current, voltage, and power curves for $1 \Omega$ load and ESR conditions are given in Figure 4 (e). The simulation results will be compared with the experimental results in the next parts.

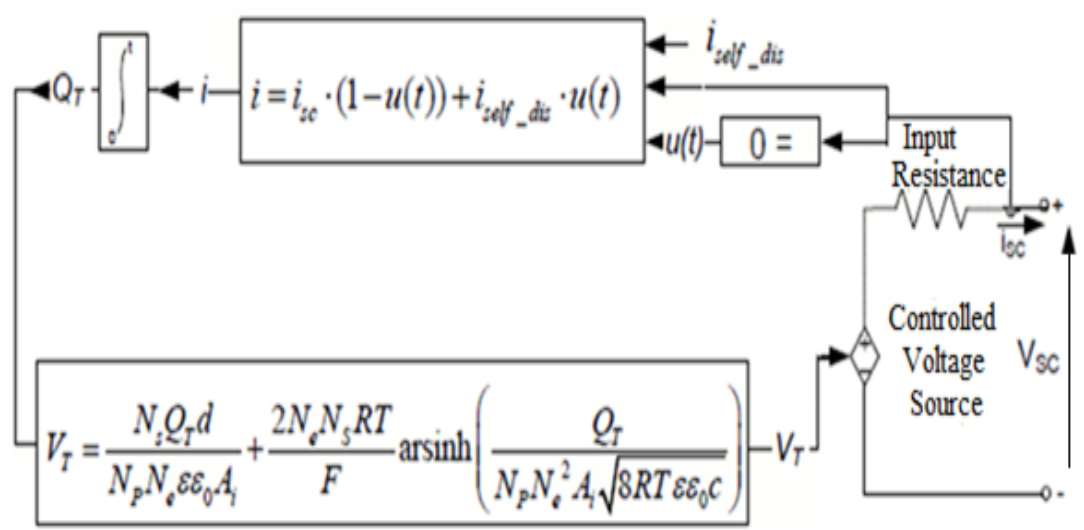




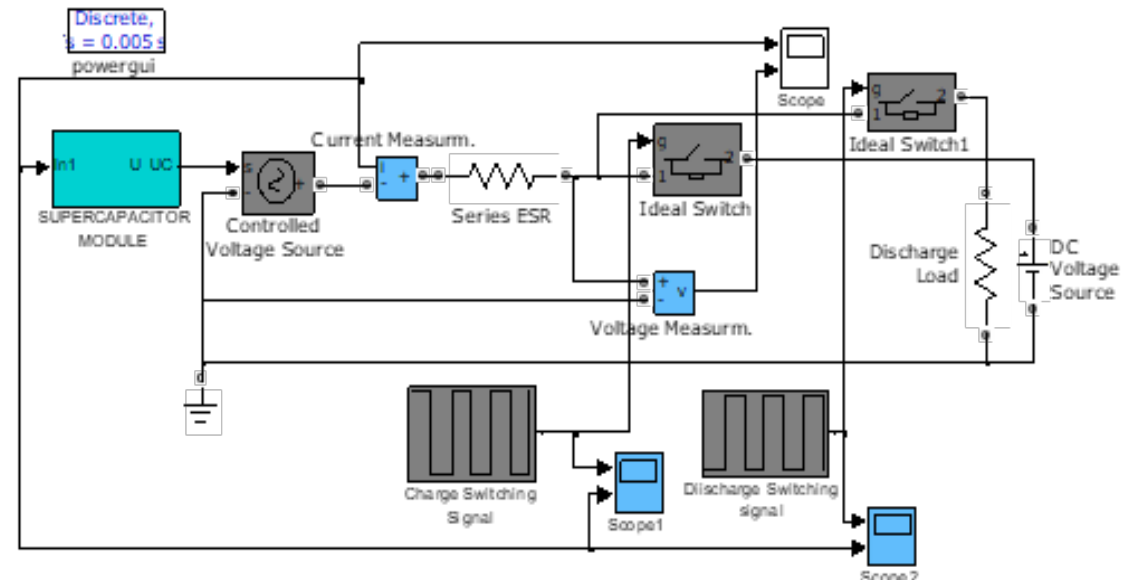

(b)

Figure 3. (a) Equivalent model for supercapacitor block.

(b) The SCs MATLAB/Simulink model with the charge and discharge setup.

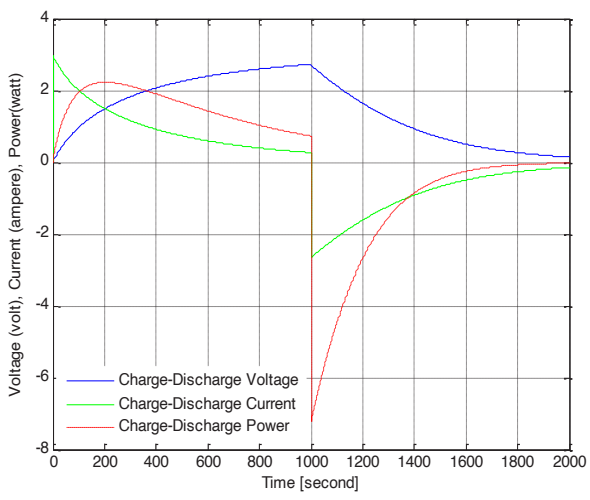

(a)

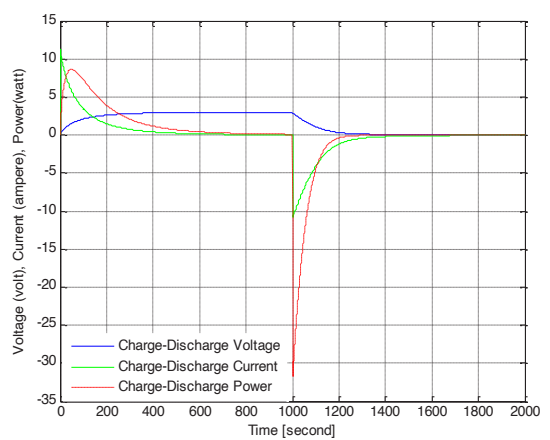

(c)

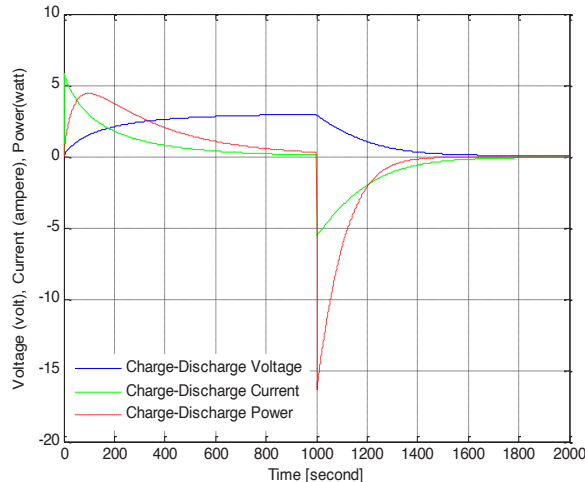

(b)

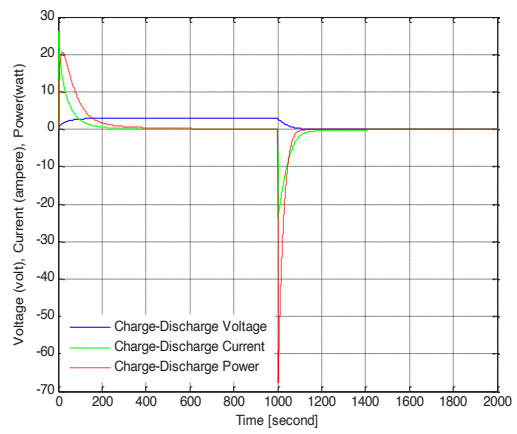

(d) 


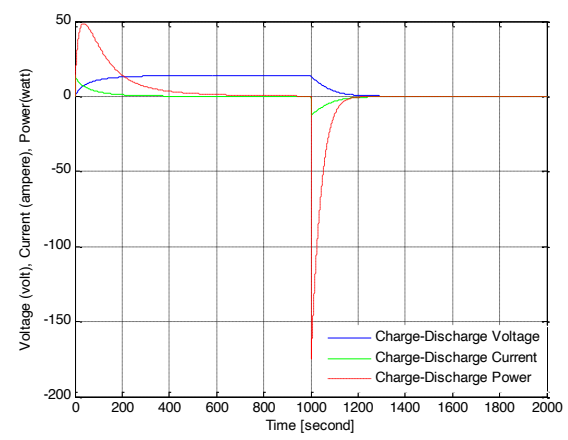

(e)

Figure 4. For a single capacitor charge/discharge conditions current, voltage, and power curves for $1 \Omega$ (a), 0.5 $\Omega$ (b), $0.25 \Omega$ (c), $0 \Omega$ (only for ESR) (d) resistances, (e) for a single module charge/discharge current, voltage, and power curves for $1 \Omega$ load.

\subsection{Design of Supercapacitor Module}

Supercapacitors do not provide a sufficient amount of constant current alone and cannot reach the desired level of voltage. So, it was required to design a module to obtain the desired current and voltage values by connecting supercapacitors in series and parallel. Therefore, a module with a maximum voltage capacity of $5 \times 2.7=13.5 \mathrm{~V}$ was created by connecting five pieces of $310 \mathrm{~F}, 2.7 \mathrm{~V}$ supercapacitor in series. These modules were developed to design supercapacitor modules by using the twenty pieces of supercapacitors. That could be connected in parallel to $12 \mathrm{~V}$, $24 \mathrm{~V}$, and $48 \mathrm{~V}$ bus voltages through different types of connections. While high levels of voltage are obtained by connecting the modules in series, high levels of current are obtained by connecting them in parallel. The system intended for the utilization of the module with $24 \mathrm{~V}$ and $12 \mathrm{~V}$ bus voltages seemed appropriate to connect the modules in doubles as series and parallel. When all the modules are connected in series, utilization in a $48 \mathrm{~V}$ system can be possible. The circuit model and the printed circuit diagram, which are designed in Eagle software for this connection, are shown in Figure 5. 


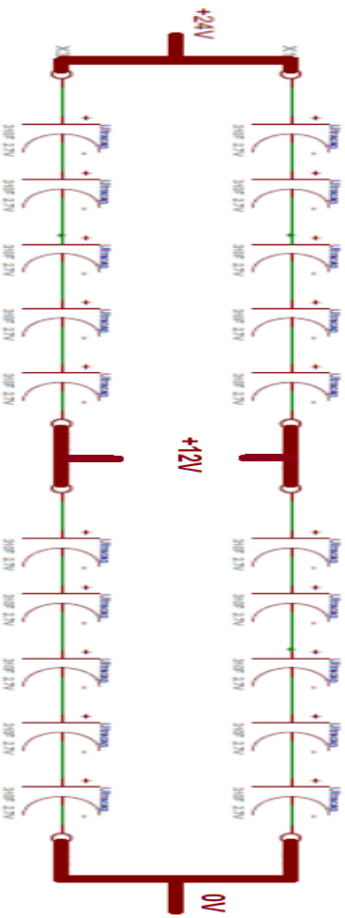

(a)

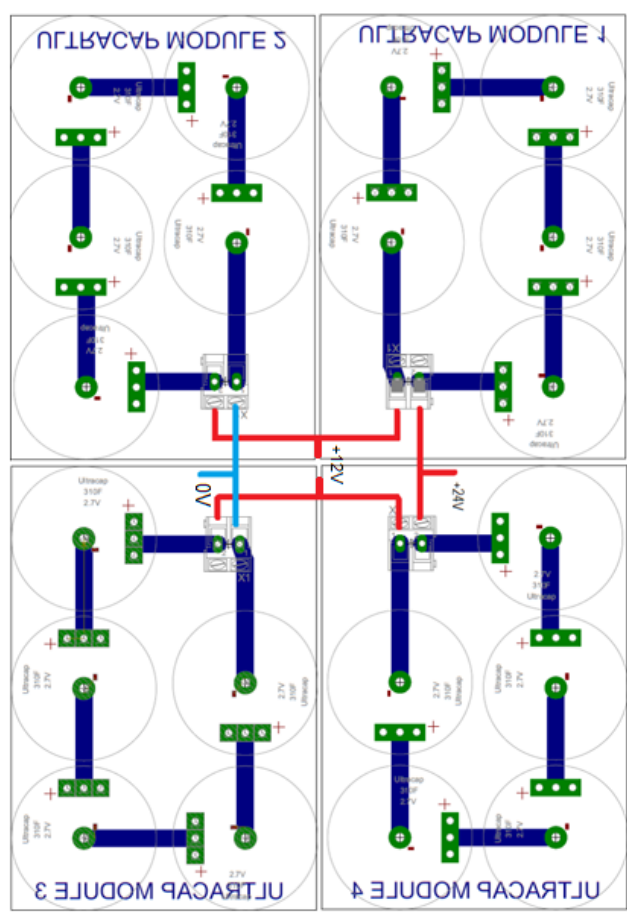

(b)

Figure 5. Circuit of supercapacitor module (a), printed circuit board wiring diagram (b).

\section{RESULTS AND DISCUSSIONS}

As the catalog data of the SCs used did not give the charge-discharge curves, and to get more information about $\mathrm{SCs}$, charge/discharge tests needed to be performed. These tests were also used to control the effect of different load conditions and to confirm their suitability within the module structures for the system to be established. The experimental setup given in Figure 6 was developed for this purpose.

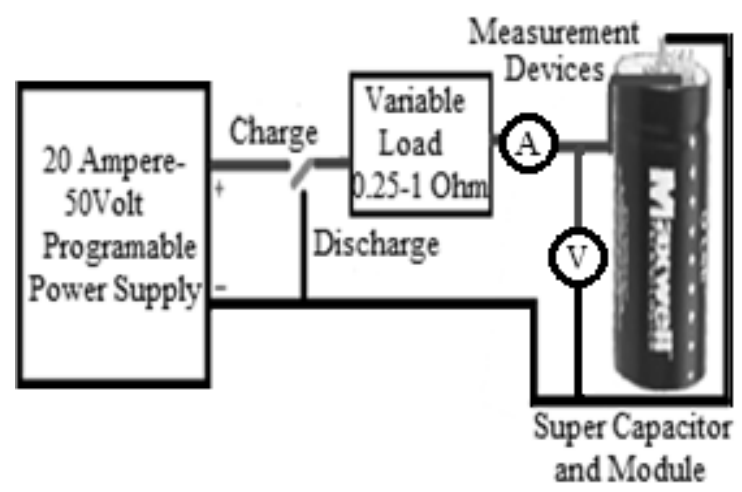

(a)

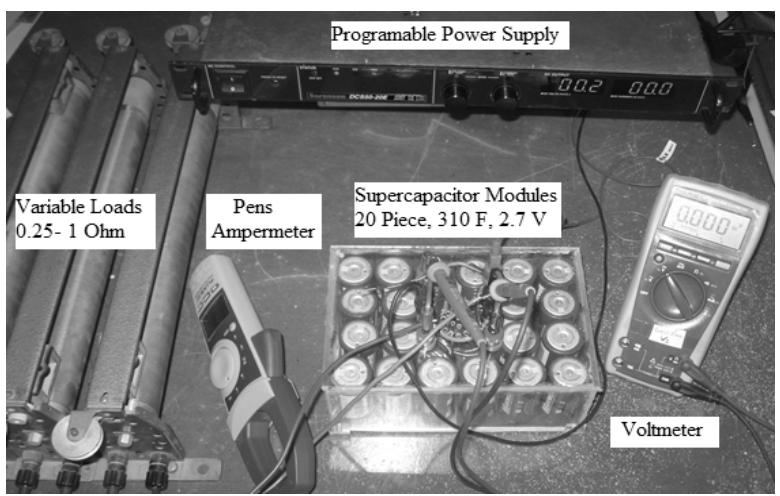

(b)

Figure 6. Circuit diagram for testing supercapacitors (a), experimental setup (b). 
The charge and discharge tests of a single supercapacitor for $2.85 \mathrm{~V}$ charge voltage were conducted initially for different load conditions to find out the instant current, charging time, and the instant power values of the supercapacitor in the experimental setup. The data obtained at the end of measurements were used to get the current, voltage, and instant power graphics given in Figures 7 and 8 for charge-discharge conditions. In the measurements given in Figure 7, supercapacitors in different load conditions were charged up to $2.85 \mathrm{~V}$ levels, which is the maximum level allowed. In these conditions, the charge time gets longer for high series resistance, and it gets shorter for small resistance. Whereas it takes 20 minutes for $1 \Omega$ series resistance, it takes as short as 4 minutes in short circuit condition.

If we make a time constant analysis for these capacitors, the time constant can be defined as $\tau=R$. $C$, and it can be calculated for $1 \Omega$ load and $310 \mathrm{~F}$ capacitors theoretically as $\tau=1 \times 310=310$ seconds. On the other hand, the time constant can be calculated from Figure 7 (a-d) experimentally. If we find the value $V_{o} / e$ and mark it on the graphics, the cross graphic time value shows the experimental time constant of the capacitors. The values are seen suitable with the theoretical results with a little different depending on the capacitor's input resistance, cable, and measurement devices resistances.

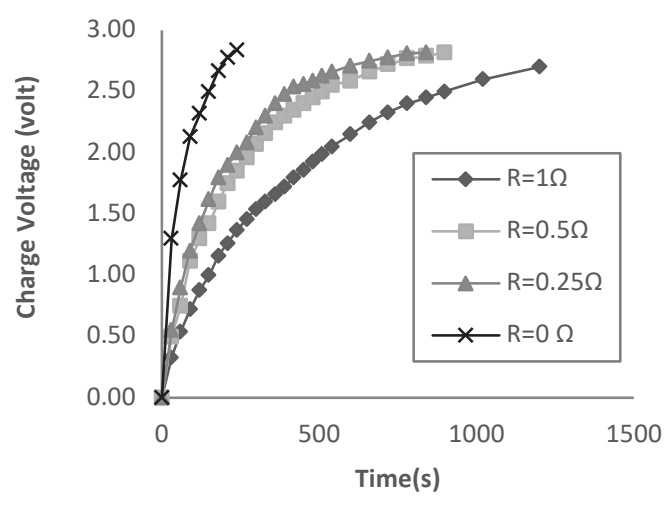

(a)

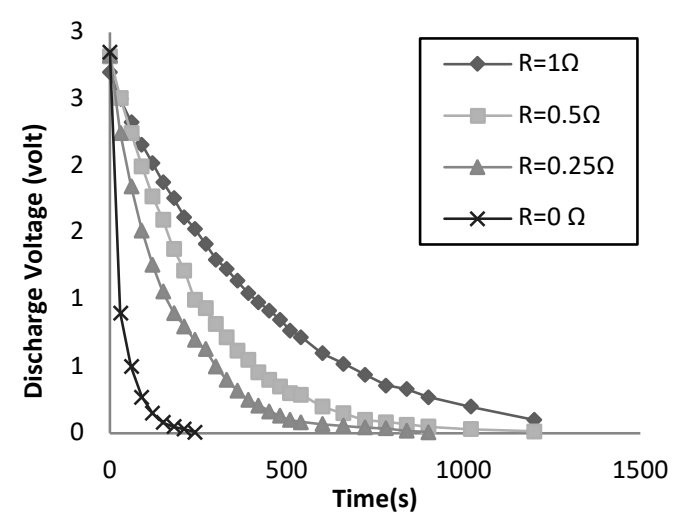

(c)

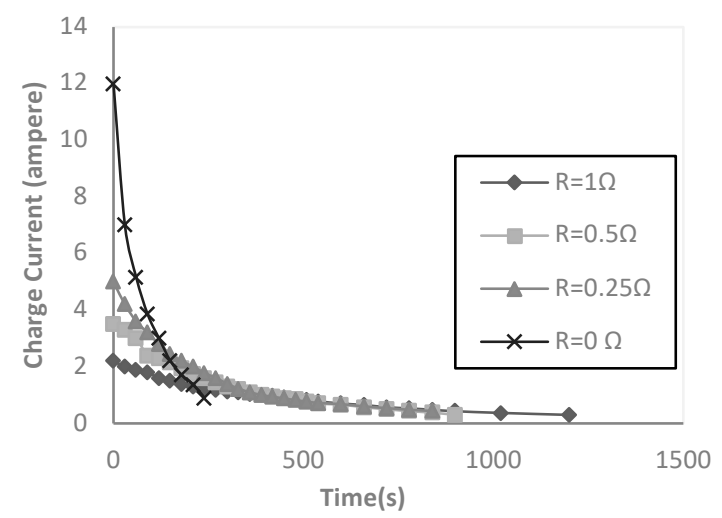

(b)

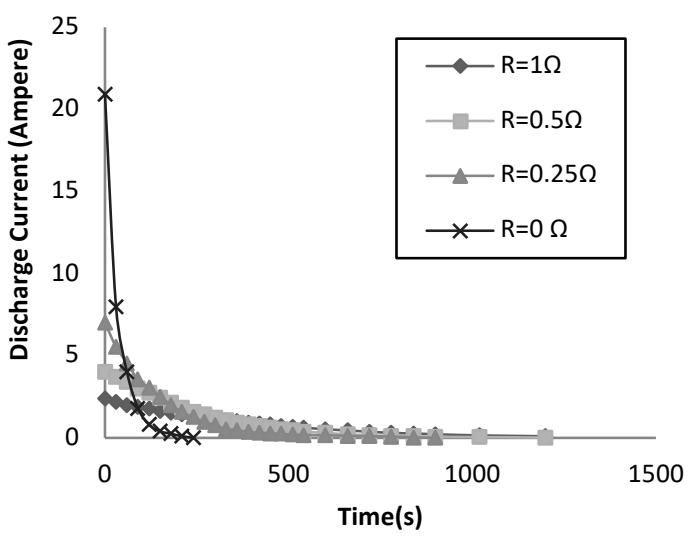

(d)

Figure 7. For a single capacitor and different resistance charge voltage (a), and current (b), discharge voltage (c), and discharge current (d). 
In the measurements given in Figure $8(\mathrm{a}-\mathrm{b})$, supercapacitors were charged at $2.85 \mathrm{~V}$ level and discharged at different load conditions. In these conditions, it is observed that whereas the time gets longer for high series resistance, it gets shorter for low resistance. Whereas it takes 20 minutes for $1 \Omega$ series resistance, it takes even shorter than 4 minutes in short circuit condition.

The results given in Figure $8(a-b)$ include the instant power values estimated by using the constant current and voltages that emerge during charge and discharge of supercapacitors up to $2.85 \mathrm{~V}$ level. In these conditions, whereas the time gets longer for high series resistance, it gets shorter for low resistance. Another issue seen in these graphs is that when a certain level of voltage is reached in instant charge condition, the maximum power is drawn. During the discharge condition, the SC voltage will be at the highest level and give the maximum current. Maximum instant power is drawn at first, and then it has seen an exponential decrease in time. It was observed, in a short circuit condition, that a single supercapacitor could emit $60 \mathrm{~W}$ instant power. $80 \%$ of this power is consumed in the first 30 seconds, and $98 \%$ of it is consumed in the first 60 seconds. While the power drawn gets decreased in different load conditions, the discharge time gets longer. This is an advantage during charging and instant power drawing.

In the further stage of the experimental study, charge and discharge tests of a single supercapacitor module, which consists of five series SCs for $15 \mathrm{~V}$ charge, were conducted for $1 \Omega$ load condition to reveal the constant current, charging time, and the instant power values. The data obtained at the end of the measurements were used to get the current, voltage, and instant power graphics given in Figure 8 (c-d) for charge-discharge conditions.

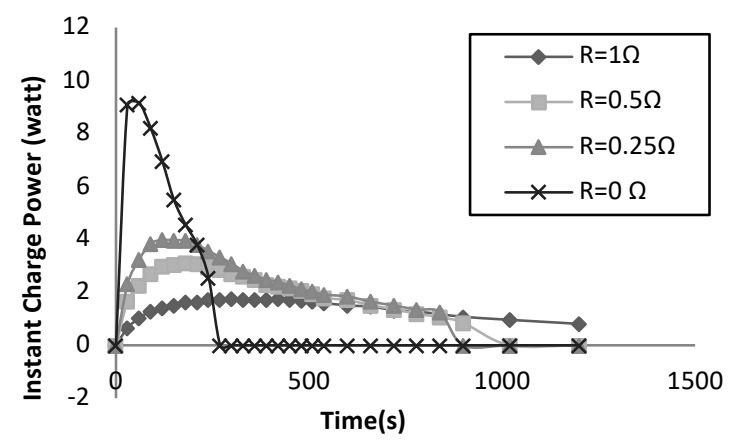

(a)

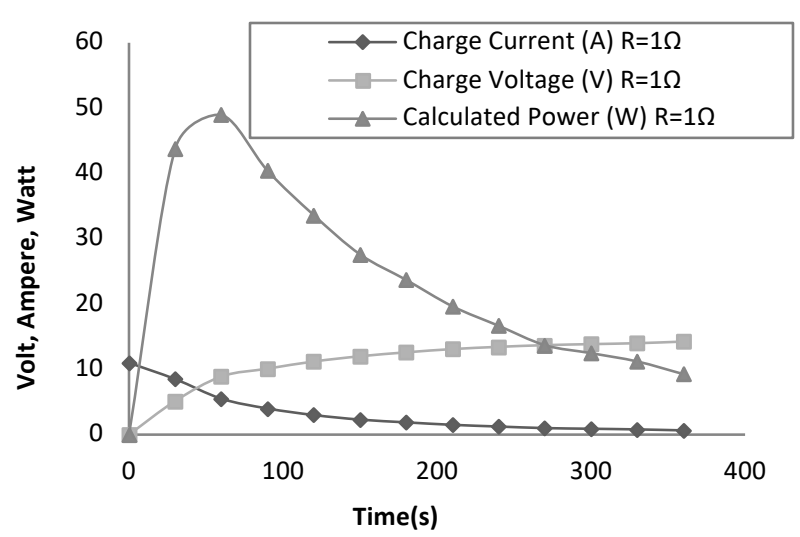

(c)

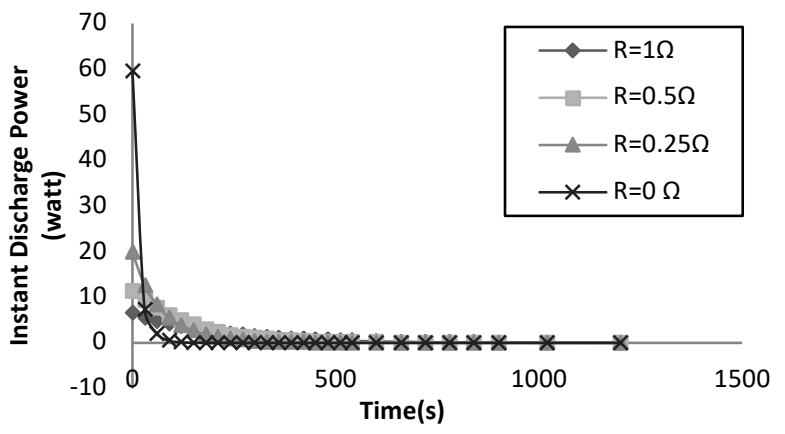

(b)

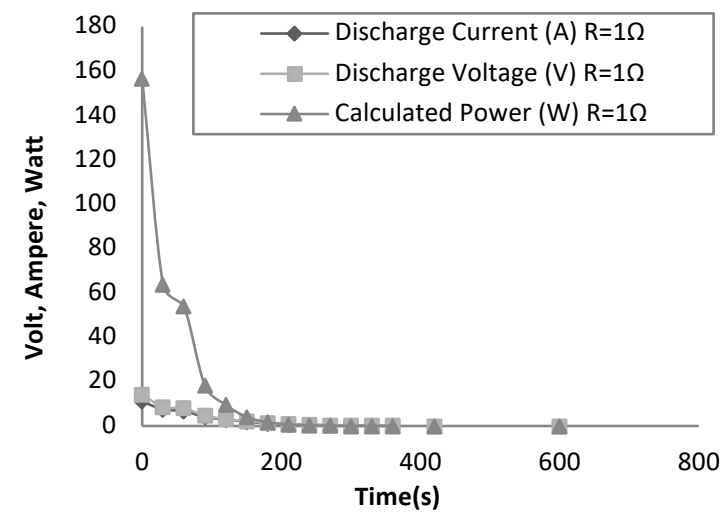

(d)

Figure 8. For a single capacitor and different resistance conditions charge (a), and discharge (b) instant power. For a single module and charge (c), discharge (d) conditions current, voltage, and power curves. 
The experimental results in Figure 8 (c-d) show the observation to see the charge and discharge conditions of the module obtained when connecting five pieces of SCs in series by using $1 \Omega$ series resistance. The maximum current of $10 \mathrm{~A}$ and $50 \mathrm{~W}$ power was drawn in charge condition. The supercapacitor got fully charged in six minutes. In discharge condition, $11 \mathrm{~A}$ of current was drawn for $1 \Omega$ load resistance, and initially, $160 \mathrm{~W}$ instant power was consumed. $30 \%$ of this power was consumed in the first minute, and the power consumed in two minutes decreased lower than $10 \%$ of the initial value. As our power supplies and measurement tools did not allow us to reach higher current and voltage levels, measurements at lower resistance could not be performed. The measurements are observed to be in conformity with the catalog data and to be able to meet the need.

Considering that the voltage and current capacities will almost double when two series and two parallel module connections are made for the same load conditions, we can say that $44 \mathrm{~A}$ of instant power can be drawn for $24 \mathrm{~V}$ bus voltage. In this case, it would be possible to drive around $1100 \mathrm{~W}$ instant power from the supercapacitor module designed. This would significantly decrease the constant voltage drops and the aging that might happen in batteries. This study will be further tested through other studies by connecting the supercapacitor module in parallel with the batteries. It is also possible to draw shorter-term instant currents for lower load resistances. Detailed results of the measurements are presented in the table in Appendix 1.

The experimental results show that the SCs have more superiority than conventional capacitors and other storage devices in many ways. It is possible to obtain instantaneous high currents without voltage drops as shown in the results. The module structure strengthens this demand more efficiently. This cycle can be repeated thousands of times without any deformation in SCs.

At last, a comparison time of experimental and simulation results for charge and discharge of SCs for different resistors is given in Table 4. The table shows that the experimental and simulation results are suitable for each other with a neglected small error of less than 0.01 . The inconsistency between some power results depends on the multiplication of values, because of the square of error reduces the values. The table shows that, for big value loads and low power consumption, the SCs can give more than 1000 seconds of energy. These values are enough for instantaneous power generation and consumption. These values can be rated depending on the high power generation and consumption ratio. This is possible in the designed module with increasing the capacitor values and connecting them series and parallel.

Table 4. Comparison timetable of experimental and simulation results.

\begin{tabular}{|c|c|c|c|c|c|c|c|c|c|c|c|}
\hline Resis & ice Value & & $\Omega$ & & & 0.2 & & & & $1 \Omega($ & ddule) \\
\hline $\begin{array}{r}\text { Charg } \\
\mathrm{S}\end{array}$ & $\begin{array}{l}\text { Discharge } \\
\text { ation }\end{array}$ & 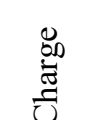 & 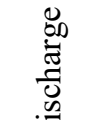 & 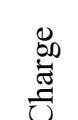 & $\begin{array}{l}0 \\
.0 \\
\bar{\Xi} \\
\bar{J} \\
.0\end{array}$ & \begin{tabular}{l}
8 \\
\multirow{\Xi}{*}{}
\end{tabular} & 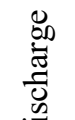 & 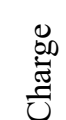 & 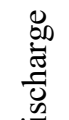 & 总 & 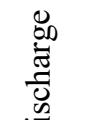 \\
\hline Voltage & Simulation & 1200 & 1200 & 900 & 900 & 840 & 840 & 240 & 240 & 420 & 420 \\
\hline $\begin{array}{c}\text { lime } \\
\text { (second) }\end{array}$ & Experiment & 1200 & 1200 & 900 & 900 & 840 & 840 & 240 & 240 & 420 & 420 \\
\hline Current & Simulation & 1200 & 1200 & 900 & 900 & 840 & 840 & 240 & 240 & 420 & 420 \\
\hline $\begin{array}{l}\text { lime } \\
\text { (second) }\end{array}$ & Experiment & 1200 & 1200 & 900 & 900 & 840 & 840 & 240 & 240 & 420 & 420 \\
\hline Power & Simulation & 1200 & 1200 & 900 & 900 & 840 & 720 & 240 & 150 & 420 & 300 \\
\hline (second) & Experiment & 1200 & 1200 & 900 & 900 & 840 & 720 & 240 & 150 & 420 & 300 \\
\hline
\end{tabular}




\section{CONCLUSION}

The detailed literature survey revealed the benefits of supercapacitors, and it also showed that their applications are continuously increasing. Another significant result of the literature survey was that it would be more appropriate to use supercapacitors in parallel with the other storage devices. Thus, it seems appropriate to design a module that would get connected to $12 \mathrm{~V}, 24 \mathrm{~V}$, and $48 \mathrm{~V}$ bus voltages in parallel for different utilizations of batteries and to study its performance. Also, it is possible to reserve peak loads and instantaneous currents using supercapacitors in many ways.

In conclusion, a module was designed by making use of 20 pieces of $310 \mathrm{~F}, 2.7 \mathrm{~V}$ supercapacitors. Chargedischarge tests for different load conditions were conducted for each capacitor and module. The changes observed in the current, voltage, and power were studied, and results were obtained about the amount of energy that could be stored and transferred to the load. Mathematical simulations and equivalent circuit models were also determined for this module, and the simulation results are repeated for different resistors in MATLAB/Simulink. The obtained experimental results showed that they conform to the simulation, catalog data, and expected theoretical results, and the modules designed could be used for several intended applications. The experimental results show that the supercapacitors have more superiority than conventional capacitors and other storage devices in many ways. A comparison timetable of experimental and simulation results for charge and discharge curve is given for the comments of all the results.

\section{REFERENCES}

Anstrom, J. R., Zile, B., Smith, K., Hofmann, H., \& Batra, A. 2005. Simulation and field-testing of hybrid ultra-capacitor/battery energy storage systems for electric and hybrid-electric transit vehicles. In Twentieth Annual IEEE Applied Power Electronics Conference and Exposition, Vol. 1: 491-497.

Azhar, A., Yamauchi, Y., Allah, A. E., Alothman, Z. A., Badjah, A. Y., Naushad, M., ... \& Zakaria, M. B. 2019. Nanoporous Iron Oxide/Carbon Composites through In-Situ Deposition of Prussian Blue Nanoparticles on Graphene Oxide Nanosheets and Subsequent Thermal Treatment for Supercapacitor Applications. Nanomaterials, 9(5): 776.

Bottu, M. Crow, M. Atcitty, S. 2012. A power electronic conditioner using electrochemical capacitors to improve wind turbine power quality. NURER Conference, Istanbul, Turkey.

Buller, S., Karden, E., Kok, D., \& De Doncker, R. W. 2002. Modeling the dynamic behavior of supercapacitors using impedance spectroscopy. IEEE Trans. on Ind. Appl., 38(6): 1622-1626.

Cheng, Z. L., Chen, W. R., Li, Q., Jiang, Z. L., \& Yang, Z. H. 2010. Modeling and dynamic simulation of an efficient energy storage component-supercapacitor, In 2010 Asia-Pacific Power and Energy Engineering Conference, pp. 1-4.

Cyrus, A. Wright, R. Hunt, G. 2006. Ultracapacitors for automotive applications, Journal of Power Sources. 154: 561-566.

Daboussi, Z., Paryani, A., Khalil, G., Catherino, H., \& Gargies, S. 2007. Li-Ion, Ultra-capacitor Based Hybrid Energy Module, Aerovironment inc Monrovia, CA.

Ehsani, M., Gao, Y., Longo, S., \& Ebrahimi, K. 2018. Modern electric, hybrid electric, and fuel cell vehicles. CRC press.

Eroğlu, H. H. 2010. Design and implementation of an ultracapacitor test system, Master Thesis, Middle East Technical University.

Faranda, R. Gallina M. \& Son, D. T. 2007. A new simplified model of double-layer capacitors, International Conference in Clean Electrical Power, 706-710.

Farzad, A. Goodarzi, A. 2011. Hybrid Lithium-ion/Ultracap energy storage systems for plug-in hybrid electric vehicles, Vehicle Power, and Propulsion Conference. 
Freeman, J., Shankar, B., Elango, M., \& Achuthan, K. 2013, Virtual labs battery and ultracapacitor characterization. In 2013 IEEE Global Humanitarian Technology Conference: South Asia Satellite (GHTCSAS) (pp. 228-233).

Glavin, M. E., Chan, P. K., Armstrong, S., \& Hurley, W. G. 2008. A stand-alone photovoltaic supercapacitor battery hybrid energy storage system. In Power Electronics and Motion Control Conference, 2008. EPEPEMC 2008. $13^{\text {th }}, 1688-1695$.

Hartmut, M. 2006. Temperature and dynamics problems of ultracapacitors in stationary and mobile applications, Journal of Power Sources. 154: 556-560.

Headquarter, G. 2013. Top 10 reasons for using ultra capacitors in your system designs, Maxwell Technologies, White Paper.

Islam, M. S., Hossain, M. B., Hossain, M. N., Alam, S. B., \& Chowdhury, M. E. H. 2010. Modeling of a double-layer capacitor with individual branch response. In Proceedings of the World Congress on Engineering and Computer Science, Vol. 2,

Jarushi, A. M. 2010. Analysis, and modelling of energy source combinations for electric vehicles, Doctoral dissertation, University of Manchester.

Jing, W. L., Lai, C. H., Wong, W. S., \& Wong, M. D. 2016. Cost analysis of battery-supercapacitor hybrid energy storage system for standalone PV systems.

Johansson, P. \& Andersson, B. 2008. Comparison of simulation programs for supercapacitor modelling. Master of Science Thesis. Chalmers University of Technology, Sweden.

Klaes, C. 2005. Maximum charging of an ultracapacitor using switch-mode rectifiers in a regeneration cycle, IEEE Vehicle Power and Propulsion Conference

Kreczanik, P., Venet, P., Hijazi, A., \& Clerc, G. 2013. Study of supercapacitor aging and lifetime estimation according to voltage, temperature, and RMS current. IEEE Transactions on industrial electronics, 61(9): 4895-4902.

Kuperman, A., Aharon, I., Malki, S., \& Kara, A. 2012. Design of a semiactive battery-ultracapacitor hybrid energy source. IEEE Transactions on Power Electronics, 28(2): 806-815.

Lahyani, A., Venet, P., Guermazi, A., \& Troudi, A. 2012. Battery/supercapacitors combination in uninterruptible power supply (UPS). IEEE transactions on power electronics, 28(4): 1509-1522.

Lajnef, W., Vinassa, J. M., Briat, O., Azzopardi, S., \& Woirgard, E. 2007. Characterization methods and modelling of ultracapacitors for use as peak power sources. Journal of Power Sources, 168(2): 553-560.

Latkovskis, L., Sirmelis, U., Grigans, L., Cernovs, J., \& Kroics, K. 2012. Capacitance and Leakage Current Balancing for Supercapacitive Energy Storage System/Kapacitāšu Un Noplūdes Strāvu Balansēšana Superkondensatoru Enerǵijas Uzkrājējsistēmai. Latvian Journal of Physics and Technical Sciences, 49(6-I): $3-12$.

Lee, J. 2015. Ultracapacitor applications for uninterruptible power supplies (ups), White Paper, Maxwell Technologies.

Libich, J., Máca, J., Vondrák, J., Čech, O., \& Sedlaříková, M. 2018. Supercapacitors: Properties and applications. Journal of Energy Storage 17: 224-227.

Manandhar, U., Ukil, A., Beng, G. H., Tummuru, N. R., Kollimalla, S. K., Wang, B., \& Chaudhari, K. 2017. Energy Management and Control for Grid-Connected Hybrid Energy Storage System under Different Operating Modes. IEEE Transactions on Smart Grid.

Matthias, R. Wollny, S. Sauer, D. U. 2015. Fast charging battery buses for the electrification of urban public transport-a feasibility study focusing on charging infrastructure and energy storage requirements, Energies 8 : 4587-4606.

Michalczuk, M. Grzesiak, L. M. \& Ufnalski, B. 2015. Experimental parameter identification of batteryultracapacitor energy storage system. In Industrial Electronics (ISIE), 24th International Symposium on IEEE, 1260-1265, June. 
Miller, J. M. Gianni, S. 2010. Battery and ultracapacitor combinations-Where should the converter go? IEEE Vehicle Power and Propulsion Conference (VPPC).

Monzer, A. S., Gualous, H., and Joeri, V. M. 2010. Characterization of supercapacitors matrix, Electrochimica Acta, 55(25): 7532-7537.

Murray, D. B. John, G. H. 2015. Cycle testing of supercapacitors for long-life robust applications, IEEE Transactions on Power Electronics. 30: 2505-2516.

Oldham, K. B. 2008. A Gouy-Chapman-Stern model of the double layer at a (metal)/(ionic liquid) interface, J. Electroanalytical Chem, 613: 131-138.

Ortúzar, M. E. 2005. Design, implementation, and evaluation of an auxiliary energy system for electric vehicles, based on ultra capacitors and buck-boost converter, Doctoral Thesis, Pontificia Universidad Catolica De Chile. 19-23.

Pesaran, A., Markel, T., Zolot, M., \& Sprik, S. 2005. Ultracapacitors and Batteries in Hybrid Vehicles (No. NREL/PR-540-38484). National Renewable Energy Lab. (NREL), Golden, CO (United States).

Prummer, M. Auer, J. Schneuwly, A. 2015. Ultracapacitors drive new efficiencies for hybrid systems architectures, White Paper, Maxwell Technologies.

Rawat, M. S., \& Vadhera, S. 2019. A comprehensive review on impact of wind and solar photovoltaic energy sources on voltage stability of power grid. Journal of Engineering Research, 7(4): 178-202.

Riley, N. Xu, J. 2011. Nonlinear analysis of a classical system: The double-layer capacitor, Electrochemistry Communications 13: 1077-1081.

Schneuwly, A. 2015. Ultra-capacitors improve reliability for wind turbine pitch systems, White Paper, Maxwell Technologies.

Seim, L. H. 2011. Modeling, control, and experimental testing of a supercapacitor/battery hybrid system passive and semi-active topologies, Master Thesis, Kjeller: Norwegian University of Life Sciences.

Shah, V. Kundu, A. P. \& Maheshwari, R. 2012. Improved method for characterization of ultracapacitor by constant current charging. Inter. Jor. of modeling and optimization, 2(3): 290,

Shuai, L., Wei, L. \& Wang, H. 2020. Review on reliability of supercapacitors in energy storage applications. Applied Energy, 278: 115436.

Steiner, M. Markus, K. Stanislaus. P. 2007. Energy storage system with ultracaps on board of railway vehicles, IEEE European Conference on Power Electronics and Applications.

Şahin, M. E., Blaabjerg F., \& Sangwongwanich, A. 2020. A review on supercapacitor materials and developments. Turkish Journal of Materials, 5(2): 10-24.

Şahin, M. E., Blaabjerg F., \& Sangwongwanich, A. 2021. Modelling of supercapacitors based on simplified equivalent circuit. CPSS Transactions on Power Electronics and Applications, 6(1): 31-39.

Şahin, M. E., \& Blaabjerg, F. 2020. A hybrid PV-battery/supercapacitor system and a basic active power control proposal in MATLAB/simulink. Electronics, 9(1): 129.

URL 1: BC series ultra capacitors, Data Sheet, Doc. No: 1017105.2, http://www.maxwell.com/images/documents/bcseries_ds_1017105-4.pdf, 2013 (accessed 20.05.2020).

URL 2: Murata Supercapacitor Technical Note, No. C2M1CXS-053N, https://www.murata.com/ /media/webrenewal/products/capacitor/edlc/techguide/electrical/c2m1cxs053.ashx (accessed 17.11.2020).

URL 3: Implement generic supercapacitor model, Help Files, (accessed 10.11.2020), http://www.mathworks.com/help/physmod/sps/powersys/ref/supercapacitor.html.

URL 4: Supercapacitor (EDLC) Basics (Part 1): What is a SC (EDLC)?, Murata Manufacturing Co., Ltd., https://www.murata.com/products/emiconfun/capacitor/2015/03/24/20150324-p1 (2018) (accessed 20.11.2020).

URL 5: Supercapacitor, https://www.jgnebattery.com/super-capacitor/coin-super-capacitor/5-5v-0-22f-supercapacitor.html, 2020, (accesed 07.08.2020). 
URL 6: Commercial SCs, https://www.kamcappower.com/, 2020, (accesed 07.08.2020).

Van Mierlo, J. Van den Bossche, P. \& Maggetto, G. 2004. Models of energy sources for EV and HEV: fuel cells, batteries, ultracapacitors, flywheels and engine-generators. Journal of power sources, 128(1): 76-89.

Wei, J. Zhang. Y. 2011. Load sharing techniques in hybrid power systems for dc micro-grids, Asia-Pacific Power and Energy Engineering Conference (APPEEC)

Zhang, L., Hu, X., Wang, Z., Sun, F., \& Dorrell, D. G. 2018. A review of supercapacitor modeling, estimation, and applications: A control/management perspective. Renewable and Sustainable Energy Reviews, 81(2): 1868-1878.

Zubieta, L. \& Bonert, R. 2000. Characterization of double-layer capacitors for power electronics applications. IEEE Trans. on Indus. Applic., 36(1): 199-205. 


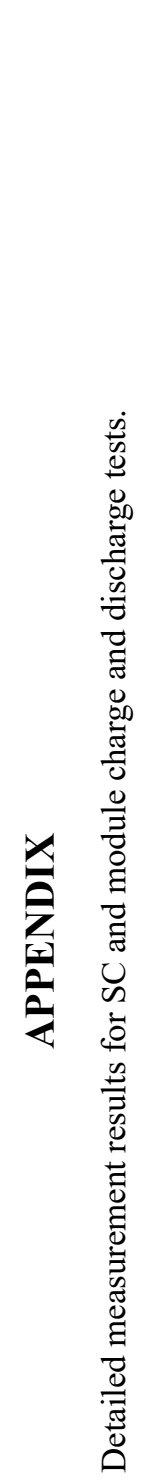

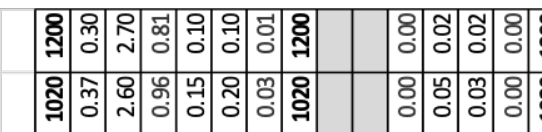

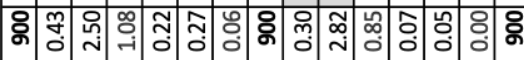

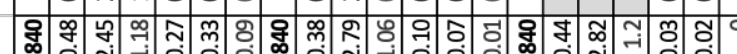

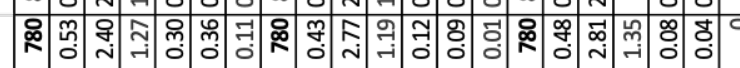

సิ 仿

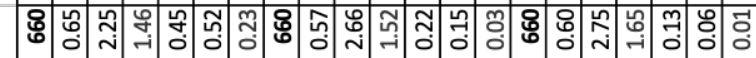

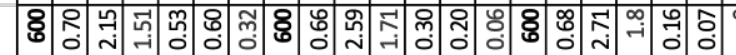

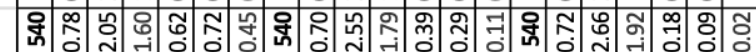

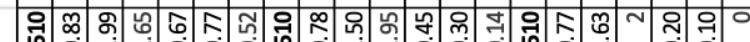

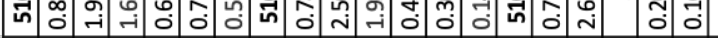

\&్య

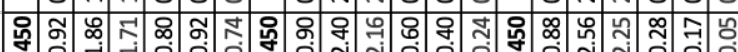

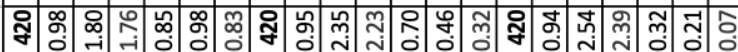

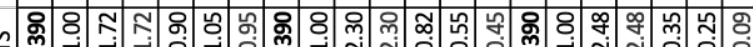

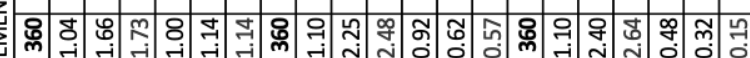

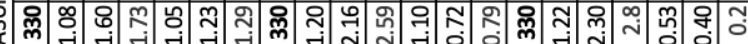

८

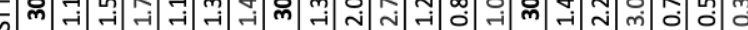

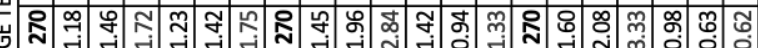

霍

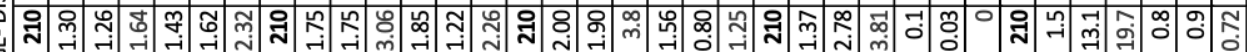

遂守

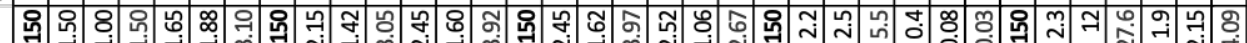

శిరం

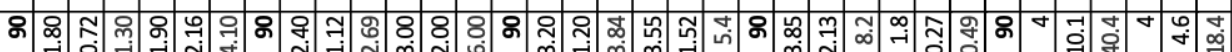

Q

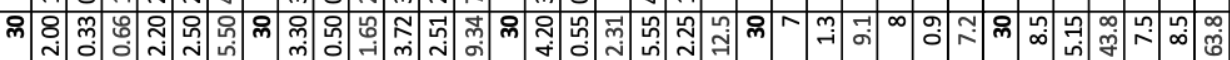

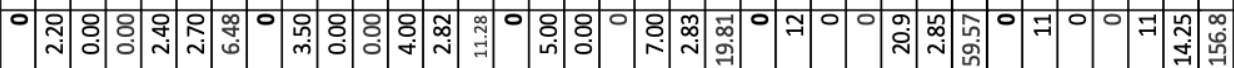

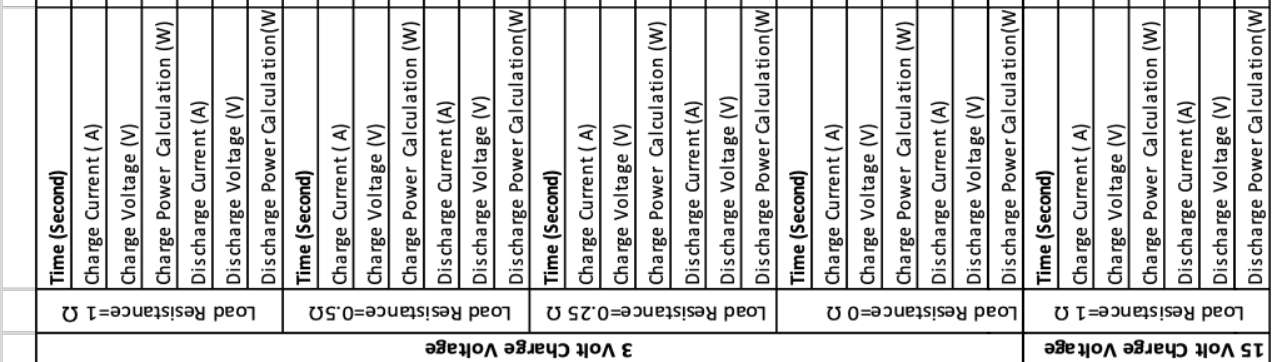

